\title{
Private Probation Costs, Compliance, and the Proportionality of Punishment: Evidence from Georgia and Missouri
}

\author{
BETH M. HUEBNER(1) AND SARAH K.S. SHANNON
}

Probation is the most commonly imposed correctional sanction, is often accompanied by supplementary costs, and can be operated by the state or private companies. Private probation is a unique sanction used in lower courts, most often for misdemeanor offenses, and is managed by third-party actors. We focus on documenting the process and unique costs of private probation, including the rituals of compliance and proportionality of punishment. We use data from interviews with individuals on private probation and local criminal justice officials as well as evidence from court ethnographies in Georgia and Missouri. For individuals on private probation, payment of monetary sanctions is a crucial way of demonstrating compliance. Yet the financial burden of added costs for supervision and monitoring creates substantial challenges.

Keywords: monetary sanctions, community corrections, municipal courts, private probation, punishment

The scope of probation is wide and deep and currently-as of the 2020 census—includes 3.5 million people, or one in every seventy-two adults in the United States (Kaeble and Alper 2020). The number of people on probation has increased fourfold in the past four decades, which has led some to term the current era as one of mass probation (Phelps 2020). Concomitant with the growth of probation has been an increase in the costs assessed by the criminal legal system overall (Martin et al. 2018; Fernandes et al. 2019) and for probation supervision more specifically (Bannon, Nagrecha, and Diller 2010; Ruhland 2019; Brett, Khoshkhoo, and Nagrecha 2020). Costs assessed to individuals on probation are commonplace and can include a monthly supervision fee, as well as expenses associated with conditions of supervi-

Beth M. Huebner is a professor in the Department of Criminology and Criminal Justice at the University of Missouri-St. Louis, United States. Sarah K.S. Shannon is an associate professor of sociology at the University of Georgia, United States.

(C) 2022 Russell Sage Foundation. Huebner, Beth M., and Sarah K.S. Shannon. 2022. "Private Probation Costs, Compliance, and the Proportionality of Punishment: Evidence from Georgia and Missouri." RSF: The Russell Sage Foundation Journal of the Social Sciences 8(1): 179-99. DOI: 10.7758/RSF.2022.8.1.08. This research was funded by a grant to the University of Washington from Arnold Ventures (Alexes Harris, PI). Partial support for this research came from a Eunice Kennedy Shriver National Institute of Child Health and Human Development research infrastructure grant, P2C HD042828, to the Center for Studies in Demography \& Ecology at the University of Washington. We thank the faculty and graduate student collaborators of the Multi-State Study of Monetary Sanctions for their intellectual contributions to the project. Direct correspondence to: Beth M. Huebner, at huebnerb@umsl.edu, UMSL, One University Blvd., St. Louis, MO 63121, United States.

Open Access Policy: RSF: The Russell Sage Foundation Journal of the Social Sciences is an open access journal. This article is published under a Creative Commons Attribution-NonCommercial-NoDerivs 3.0 Unported License. 
sion. Evidence is emerging to suggest that compliance with these costs can pose challenges (Brett, Khoshkhoo, and Nagrecha 2020), and failure to pay fines and probation costs can lead to additional sanctions including the extension of supervision and incarceration for noncompliance, among other outcomes (Friedman et al. 2022, this volume; Ruhland 2019).

During this time, there has been a growth in the use of private probation, a practice not often captured in studies of probation or official correctional statistics (Phelps 2020). Private probation is unique and separate from state or felony probation systems and is used predominantly for individuals convicted of misdemeanor, traffic, or ordinance offenses under the purview of local courts. Private probation is also distinctive in that it is managed by thirdparty, for-profit entities and often accompanied by conditions of compliance including drug testing, electronic monitoring, and specialty classes (Bellacicco 2013; Albin-Lackey 2014).

Unlike traditional probation, which was designed to provide community supervision in lieu of incarceration and based on a peer support model, many argue that private probation has become instead another way in which criminal legal institutions make money (Harris, Smith, and Obara 2019), as the burden to fund the system falls on system users (Rosenthal and Weissman 2007; Appleman 2016). Although state probation systems certainly charge people on probation for supervision and additional costs of compliance, these entities are typically funded more substantially by state tax revenues. Private probation companies, however, promise local jurisdictions that they will pay nothing for these services because all costs of supervising misdemeanor probationers will be covered by fees charged to those under supervision (Schloss and Alarid 2007). This dynamic highlights the distinct profit motive underlying private probation that is less pronounced for state agencies. Moreover, these costs of private probation are often hidden from view and are assessed without traditional due process protections, making them a part of the ever-growing shadow carceral state (Beckett and Murakawa 2012; Friedman et al. 2022, this volume).

In this article, we build on existing work on monetary sanctions and mass probation by documenting the process and related costs of private probation in two states, Georgia and Missouri. Data for the study come from a series of qualitative interviews conducted with individuals with legal debt and criminal justice decision-makers as well as court observations. Three prominent themes emerge. First, the costs for private probation are often considerable, layered, and hidden. Second, the rituals of compliance are opaque and cumbersome, particularly for those without economic means. Third, given the barriers to compliance, individuals are often sentenced to disproportionate punishment relative to those on felony probation. Taken together, our findings show that the conditions of private probation are multilayered and insufficiently regulated, resulting in punishments that are disproportionate to the severity of the offense.

\section{COSTS OF PROBATION}

More than half of people under correctional control are serving a term of probation (Maruschak and Minton 2020). Like the mass growth in prison populations over the past four decades, probation has grown to be commonplace, particularly among young Black men (Phelps 2020). Concomitantly, there has been a considerable increase in the use of private probation companies in the lower courts, which largely govern individuals charged with minor offenses such as misdemeanors and ordinance violations (Bellacicco 2013; Albin-Lackey 2014). Nationally, statistics on misdemeanor cases are lacking, but estimates show that the system is enormous, some 13.2 million misdemeanor cases are filed every year (Stevenson and Mayson 2018). Despite the long reach of misdemeanor probation generally and private probation specifically these systems are rarely studied. As a result, our review of the literature on probation costs focuses largely on state (felony) probation, except where noted.

The growth in probation has also been paralleled with an increase in the frequency of assessment and costs associated with legal financial obligations (LFOs). The use of fines associated with probation has grown, though the true scope of the phenomenon is unclear. For example, Katherine Beckett and Alexes Har- 
ris (2011) find that forty-four states charge probation fees for felony supervision. Costs for probation vary widely, some probation departments charge a monthly fee for supervision that can range from $\$ 10$ to $\$ 150$, and others assess a one-time fee ranging from $\$ 30$ to $\$ 600$ (Brett, Khoshkhoo, and Nagrecha 2020).

Probation sanctions and associated costs can be a barrier to success for people under supervision for either a felony or misdemeanor conviction (Diller, Greene, and Jacobs 2009; Ruhland 2019). The emerging research suggests that many individuals on probation do not have the economic means to pay for monetary sanctions and that the costs associated with probation are stressful, given that nonpayment can be used as evidence of noncompliance (Ruhland 2019; Ruhland, Holmes, and Petkus 2020). The assessment of indigence is also not consistent and waivers do not appear to be granted routinely (Harris et al. 2017; Link, Hyatt, and Ruhland 2020). Unpaid costs can lead to incarceration or additional sanctions (Colgan 2014; Heaton, Mayson, and Stevenson 2017; Ruhland 2019). Further, time requirements are considerable because individuals must attend regular meetings with correctional staff, judges, and clerks (Evans 2014; Doherty 2016). In short, probation costs can exacerbate the harms of community supervision and are magnified for those without financial means (Brett, Khoshkhoo, and Nagrecha 2020).

These dynamics are intensified in misdemeanor courts, where private probation companies provide supervision in at least a dozen states (see table 1). Private probation departs from traditional state-run probation systems in several ways. First, individuals sentenced to private probation are responsible for all probation-related costs, including any courses or treatment services required as conditions of supervision, resulting in what some call an "offender-funded system" (Ramachandra 2018). Some state statutes explicitly mandate that the costs of probation should only be paid by the individual-without support from the state, which is different from felony probation and often leads to higher supervision costs for clients (Schloss and Alarid 2007). In Missouri, for example, state law indicates that "neither the state of Missouri nor any county of the state shall be required to pay any part of the cost of probation and rehabilitation services provided to misdemeanor offenders." ${ }^{1}$ Scholars contend that the costs for private probation are larger than those of traditional probation, but most courts do not track the amount private probation companies collect in fees or mandate reporting by agencies (Teague 2011; Albin-Lackey 2014).

Second, although supervision costs are common to probation, evidence is emerging to suggest that individuals supervised by private probation companies are more likely to be assessed specialty fees for elements of supervision such as mandated treatment, electronic monitoring, and drug testing (Albin-Lackey 2014; Latessa and Lovins 2019). Individuals supervised by private probation departments have reported that they felt that they were being threatened with revocation and additional sanctions for the inability to pay and subject to inappropriately aggressive and hostile collection tactics (AlbinLackey 2014; Shannon 2020). ${ }^{2}$

Third, individuals on private probation are not offered the same procedural protections as those under state supervision. Misdemeanor cases are typically not covered by Bearden $v$. Georgia, which prohibits probation revocation solely for failure to make payment (Williams, Schiraldi, and Bradner 2019). ${ }^{3}$ In addition, individuals in municipal courts are rarely afforded the services of a public defender given that cases that typically do not result in incarcera-

1. Revised Statutes of Missouri (RSMo) $§ 559.604$ (2017). In Georgia and Missouri, some municipalities have made the decision to manage their own probation services locally, but the lack of state funds for these services makes the two systems fundamentally different.

2. This focus on collections with the threat of extended sanctions and disciplinary control is not dissimilar to the nineteenth-century history of working-class industrial life insurance in Britain that involved agents of private fraternal insurance companies extracting premiums from poor families while ostensibly, though debatably, inculcating them with the value of thrift (see O'Malley 1998).

3. Bearden v. Georgia, 461 U.S. 660 (1983). 
tion, like those on private probation, are not afforded representation (Alarid and Schloss 2009). Finally, oversight of private probation companies is far less than of traditional staterun systems (Albin-Lackey 2014; Harris, Smith, and Obara 2019; Montes and Mears 2019). Even in states with a formal state oversight system in place, such as Georgia and Tennessee, evidence suggests that further structure is needed and that the current private probation system puts individuals on probation at risk (Wilson 2018).

\section{RITUALS OF COMPLIANCE}

IN MUNICIPAL COURTS

Emerging evidence suggests unique procedural costs of punishment in municipal courts (Natapoff 2018; Mayson and Stevenson 2020). Researchers have documented an arduous process of punishment in misdemeanor courts because people must undertake a significant burden to comply with formal legal proceedings, which often includes a performance to offer evidence that they take responsibility, or display accountability for the offense (KohlerHausmann 2013, 2018; Martin, Spencer-Suarez, and Kirk 2022, this volume). The private probation process is particularly opaque and the rituals of compliance are more involved (Teague 2011), yet oversight of the system is scant given what many perceive as the low-stakes nature of municipal courts (Huebner and Giuffre 2022, this volume; Mayson and Stevenson 2020). Individuals also face many barriers to adherence to court mandates, such as transportation, which further complicate the process (Cadigan and Kirk 2020).

\section{Proportionality of Private Punishment}

One key goal of an equitable and appropriate criminal justice system should be to allocate sentences and judgments that are proportional to the gravity of the offense. Legal scholars Norval Morris and Michael Tonry (1990) argue that a void separates probation and prison sentences in the United States in which individuals on the fringe of these two sentences are not appropriately considered (see also Petersilia 2003). They contend that probation in general is an attempt to use community supervision to account for individuals who occupy this disci- plinary lacuna, but the result is an often misguided and poorly adjudicated series of sentences that fail to rehabilitate the individual effectively. Probation was originally designed as an alternative to prison and a way to provide rehabilitative services to people in the community (Corbett 2015). The net of probation, however, has widened bringing people under the supervision of the carceral state who would have never been subject to incarceration (Phelps 2020).

The challenge of proportionality is particularly evident in misdemeanor courts, especially those that engage private probation systems. Scholars have argued that private probation, when imposed on individuals with misdemeanor convictions, is used for the wrong group of people and implemented in such a way that predictably leads to failure (Bellacicco 2013; Klingele 2013). In addition to the disproportionate costs of private probation, individuals under this type of correctional control are not offered the same safeguards and services, including housing or employment services, something that is commonplace with traditional felony probation (Bellacicco 2013). The use of private probation is disproportionately harmful to individuals with fewer economic means in that private probation agencies often criminalize such individuals' inabilities to pay the fees associated with their probation terms (Ramachandra 2018). The profit-driven nature of this system, in which the survival of private companies depends on the ability to raise revenue, means that individuals are less likely to be given a reprieve when they cannot pay (Teague 2011). Moreover, the practices of private probation companies are subject to very little scrutiny or oversight in most states, allowing profit motive to muddle access to reprieve when individuals cannot pay (Ramachandra 2018).

One illustration of the disproportionate nature of private probation is pay-only supervision, wherein individuals unable to pay their fines and court costs immediately are placed on court-ordered probation solely for monitoring and collecting court debt. The longer it takes individuals to pay off their debts, the more individuals must pay in supervision fees and the more time served on supervision, which in some cases can amount to more monetary 
sanctions than originally ordered, inflicting great financial hardship (Albin-Lackey 2014). In this way, the payment process puts defendants' freedom on "layaway" until they have the financial means to comply fully (Pattillo and Kirk $2021,2)$. Private probation also has a burdensome performative element in that individuals are required to make multiple trips to the courtroom to comply, whereas those with more economic means can remedy debt in one trip (Bellacicco 2013).

Overall, the goal of this work is to build on emerging scholarship on mass probation to document the role of private probation in lower courts, particularly around the economic and procedural costs of compliance. Our research question asks whether and how the dynamics of probation costs and rituals of compliance impact the proportionality of private probation sentences? We draw on evidence from interviews with 130 individuals sentenced to probation, ninety court decision-makers, and more than four hundred hours of court observations across two states.

\section{STUDY SITES}

Data for this study come from two states, Georgia and Missouri. Unlike other states in the Multi-State Study of Monetary Sanctions, both Georgia and Missouri operate private probation systems in the lower courts. Even so, the legal and procedural nature of these systems varies between these two states, which allows for a more nuanced understanding of the use of private probation in practice. Although the true scope of private probation is unknown, table 1 provides insight into the nature of private probation in the United States based on our survey of publicly available documentation of private probation systems. At the time of this analysis, only twelve states had documented private probation systems. In our review, we find that most of the systems are managed at the county or local level under little state or systematic oversight. Many private agencies simply enter into private contracts with the court and have no formal reporting requirements. In contrast, some states, including Georgia, have implemented oversight bodies. For example, Tennessee has developed a Private Probation Service Council, the stated goal of which is ensuring that uniform professional and contract standards are practiced and maintained by private corporations, which are regularly audited.

Most private probation agencies are allowed to charge, at minimum, $\$ 30$ per month, although two states, Tennessee and Alabama, allow for means-tested financial assessments. The term of supervision traditionally lasts for two years, although variation is substantial. Legislation rarely addresses the costs of services and treatment required by the court, and except for Michigan, little, if any state funding is allocated to private probation services. Again, Missouri has designated in state statute that all costs of private probation should be covered by the defendant." "The following discussion describes how these elements manifest in the study communities.

\section{Missouri}

Individuals placed on probation for a felony are supervised by the Missouri Department of Corrections; individuals with misdemeanor or ordinance violations are disallowed by statute to be supervised by the state probation and parole officers. In 1992, as a cost-saving measure, the state of Missouri passed legislation allowing for private entities to provide probation services in municipal courts. ${ }^{5}$ Some municipal courts in the state have elected to partner with private probation agencies; others use local municipal or county staff. No systematic accounting of the number of private probation organizations is undertaken.

Private organizations that wish to provide probation services must make an application with circuit courts, but the law provides no guidelines for the approval of an agency, leaving each court to develop its own. Contracts can be in place for three years, and there are no statutory requirements for the qualifications of program staff. The only caveat is that the agency and a judge or elected official may not

4. For more information, see Intervention, "Criminal Justice Services," 2021, https://www.int-cjs.org (accessed August 10, 2021),

5. RSMo § 559.600 . 


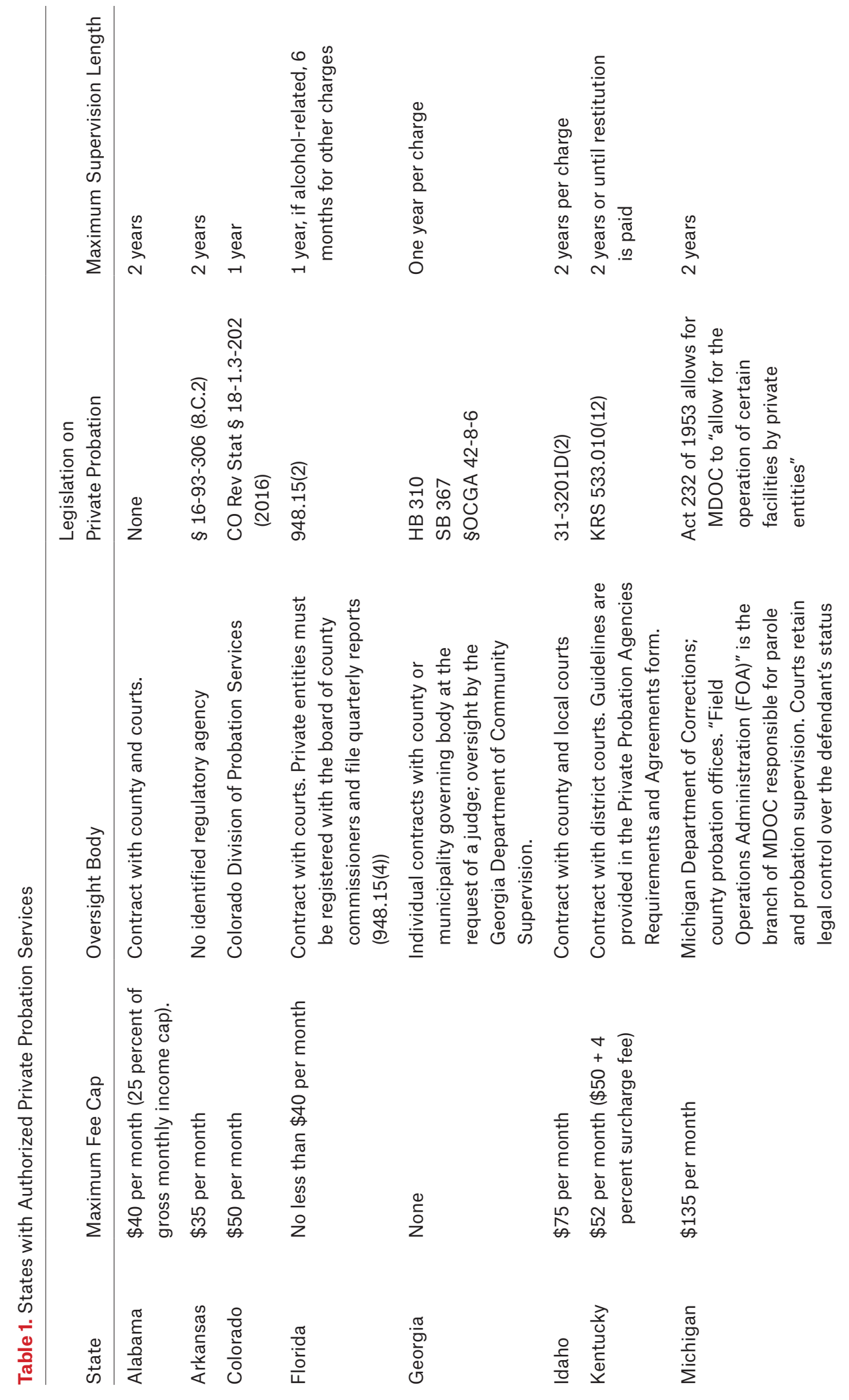



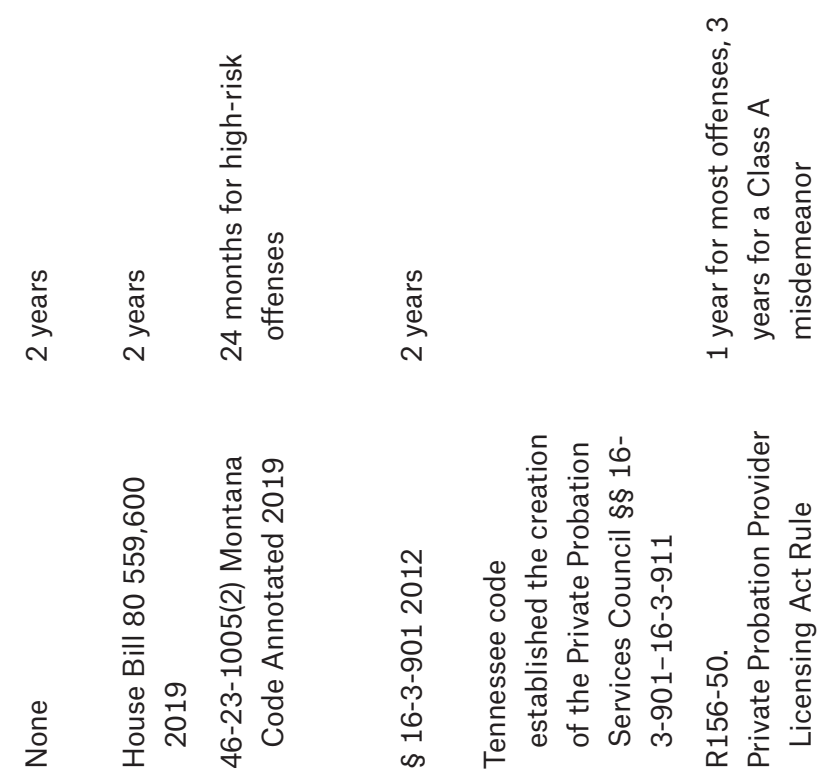

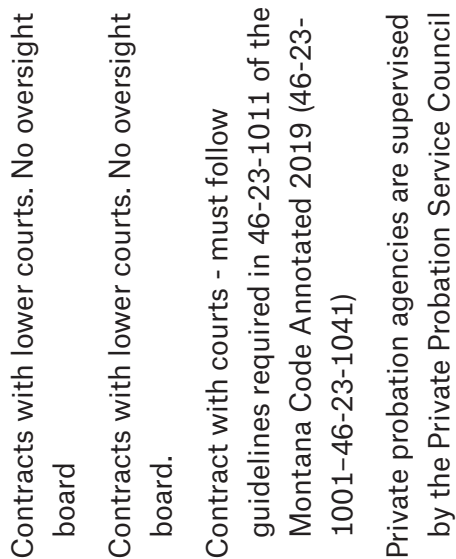

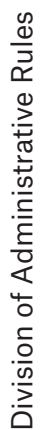

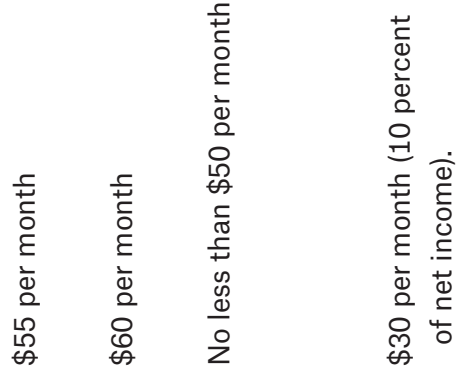

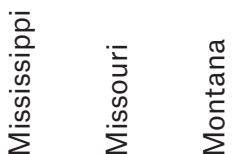
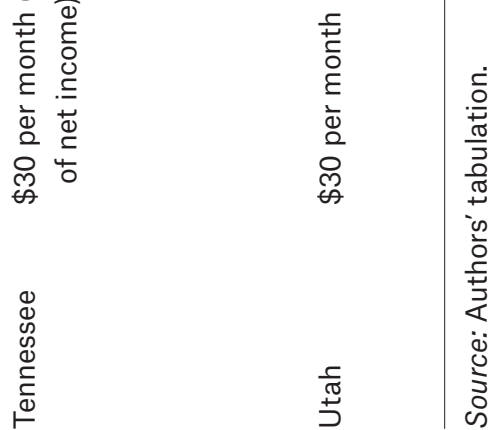
have any relationship or mutual financial interest. State statutes have changed very little since the original legislation was passed, and Missouri does not require verification of fees collected.

\section{Georgia}

Georgia law requires that all felony-level probationers be supervised by the state Department of Community Supervision but explicitly disallows the state from supervising misdemeanor probationers, who must be supervised by local or private entities instead. ${ }^{6}$ Since 1991 , Georgia law has allowed judges of county and municipal courts to contract with private corporations to provide probation supervision and collect money for misdemeanor probationers with unpaid monetary sanctions. ${ }^{7}$ Currently, twentyfour private probation companies provide services in Georgia counties and cities. ${ }^{8}$ Information is not publicly available on supervision fees and other costs assessed by these companies; however, media reports from Georgia cite monthly supervision fees between $\$ 25$ and $\$ 45$ in addition to start-up fees (\$15) and daily fees of $\$ 7$ to $\$ 12$ for electronic monitoring (Rappleye and Riodian-Seville 2012). According to the Council of State Government Justice Center (2016), private probation companies in Georgia collected $\$ 121$ million in fines, fees, restitution, and other payments. In 2015, in response to the growing number of legal cases filed against private probation companies in the state, the Georgia legislature created the Board of Community Supervision to provide oversight to misdemeanor probation in the state. ${ }^{9}$

Georgia courts can sentence people convicted of misdemeanors to pay-only probation solely for the inability to pay the fines and fees owed at the time of sentencing..$^{10}$ The only service provided by probation officers, in this case, is the collection of payments toward the debt. The statute specifies that supervision fees for pay-only probation must not exceed three months of ordinary probation supervision fees and that collection of any probation supervision fee terminate as soon as all court-imposed fines and surcharges are paid in full. A probation officer must file a motion within thirty days to terminate a defendant's probation sentence early once all money owed is paid. ${ }^{11}$

\section{METHODS}

Data for this study were obtained from in-depth interviews with individuals with legal debt and criminal justice decision-makers as well as court observations in Georgia and Missouri as part of a larger study of monetary sanctions (Harris, Pattillo, and Sykes 2022, this volume). In total, 130 individuals with legal debt were interviewed; seventy in Missouri and sixty in Georgia. Interviews were conducted with forty criminal justice stakeholders in Missouri and fifty in Georgia and include defense attorneys (nine in Missouri, ten in Georgia), prosecutors (four in Missouri, six in Georgia), judges (thirteen in Missouri, sixteen in Georgia), and court clerks (eight in Missouri, seven in Georgia). We also interviewed probation and parole officers (twelve in Missouri, eleven in Georgia); two of the interviews in Georgia and one in Missouri were with individuals who supervised private probation clients. More than two hundred hours of court observations were conducted at both research sites. Individuals with current legal debt were eligible for the study, and participants were recruited using several methodologies. The research teams developed flyers

6. Official Code of Georgia Annotated (O.C.G.A.) § 17-10-3 (2010). Exceptions are made if a person is under felony supervision but also has misdemeanor convictions

7. O.C.G.A. § 42-8-100.

8. See Georgia Department of Community Supervision, “Misdemeanor Probation Oversight," 2021, https:// sites.google.com/a/dcs.ga.gov/department-of-community-supervision2/provider-information-list (accessed August 10, 2021).

9. State of Georgia, House Bill (HB) 310 (2015).

10. O.C.G.A. § 42-8-103.

11. O.C.G.A. § 42-8-103(b). 
that were distributed to state probation offices and local service providers, and notices that were placed on Craigslist and Facebook. Interviews lasted approximately one hour and were conducted at local service agencies, probation and parole offices, libraries, and other local establishments. Criminal justice decision-makers were recruited through personal contacts and snowball sampling (Biernacki and Waldorf 1981).

Individuals with legal debt and criminal justice stakeholders were interviewed using a semi-structured interview protocol (Harris, Pattillo, and Sykes 2022, this volume). We did not query participants with legal debt or stakeholders specifically on the use of private probation, although we did ask about a range of sanctioning more broadly, including traditional felony probation. The themes described here were identified organically as part of our probing on the costs of contact with the criminal justice system.

\section{ANALYSIS}

We analyzed all of the data using a modified grounded theory approach, relying on both deductive and inductive coding strategies (Lofland et al. 2005). We began by identifying key themes for consideration including community supervision, court-ordered programming, discretion, and consequences of nonpayment. We also did a keyword search for private probation. Following the initial round of coding, we constructed memos to identify themes and patterns (Charmaz 2006). Through this coding process, three primary themes emerged: the hidden costs of private probation, proportionality, and the rituals of compliance. We also used narrative and observational data to document the high cost and cumulative nature of probation, overall, that provides context to the two main themes. During further rounds of coding, we identified additional themes that centered on the performative nature of compliance and the collateral consequences of private probation. We achieved interrater agreement through the consensus-building approach and documented counterfactuals to dominant themes (Miles and Huberman 1993; Charmaz
2006). We assigned pseudonyms for all participants.

\section{COST OF PRIVATE PROBATION}

Probation agencies assess two classifications of costs: supervision fees and compliance costs. For felony probation, many of these costs are set by statute or statewide policy. For example, in Georgia, the monthly supervision fee is $\$ 32 .{ }^{12}$ In contrast, monthly costs for private probation at the misdemeanor level, vary widely, are set locally by courts and providers and do not cover the costs of treatment and related programming. Compliance costs include fees for programming, such as substance abuse treatment and rehabilitative classes and drug testing, which are assessed by the judge as a condition of supervision. In both states, variation was substantial in the frequency and the nature of programming ordered and the requisite costs assessed by the misdemeanor courts.

Compliance costs were the most noted by participants. Municipal courts contract with third-party agencies to provide court-ordered treatment classes and other mandated services, and the costs can be substantial. In the lower courts in both states, we observed individuals being sentenced for misdemeanor offenses to a host of programs and treatment modalities including anger management classes, GPS monitoring, drug treatment, safe driving classes, community service, among others. For instance, one participant in Missouri reported paying $\$ 800$ for anger management classes for a misdemeanor assault conviction. In Missouri, most classes, like participation in a victim impact panel, would cost $\$ 50$ per session and have no agreed-upon duration. Other costs, such as a urinalysis, vary widely; in one Missouri municipality each screening was $\$ 20$ and some participants were mandated to provide a sample biweekly. In Georgia, such costs also vary substantially. In one misdemeanor court, ten days on electronic monitoring cost the defendant $\$ 10.50$ per day. Driving school for traffic convictions typically costs defendants $\$ 40$ or $\$ 50$ for a six-hour course, depending on the jurisdiction. Anger management courses run \$35 per session and total $\$ 700$ for a ten-week, twice 
per week course, as required in one of the Georgia municipal courts we observed.

Individuals are often sentenced to multiple sanctions, all with different costs and requirements for compliance. During our observations of a Missouri municipal court, we documented the case of a forty-year-old female. She indicated to the judge that she was on disability, but a waiver of fees was not offered. The complicated nature of punishment is detailed in this court observation.

The defendant pled guilty to trespassing and stealing, had priors, and asked the judge whether she could get on a payment plan because she was on disability. For the trespassing case, the defendant was sentenced to pay a \$250.50 fine. For the stealing case, the defendant was sentenced to two years' unsupervised probation. The defendant, as a condition of probation, was ordered to pay a $\$ 350$ fine plus court cost, complete forty hours of community service (which could be set up by the court, through the city or a nonprofit organization), and return to court in November, not violate probation, notify court of change of address, not to go to Walmart, attend shoplifting class, and pay $\$ 50$ a month for supervision costs.

The exchange was one example of the layered nature of sentencing in municipal court. The participant will be responsible for $\$ 1,200$ in supervision fees over the term of the sentence, costs associated with shoplifting classes, and fines and court costs, which altogether will likely total more than $\$ 2,000$ and be paid on a disability stipend. Compliance also required a substantial time commitment, which included attendance at classes and forty hours of community service, and the failure to consider the physical needs of the participant is a common theme echoed in work of this type (Cadigan and Smith 2021).

Participants also expressed challenges complying with supervision costs. Even small fees were hard to pay when individuals were juggling multiple financial responsibilities. Compliance with these rituals compound on themselves and conflicts with other obligations. Caroline described how her experience on probation in
Missouri included numerous mandated fees and was a challenge to balance everyday costs and compliance: "I mean like, the supervision fees and stuff are what, because that's $\$ 30$ a month and I have it for five years, so that's $\$ 1,800$ alone. So it's just, for being someone like me that can't get a job, it's really hard, especially having three kids, being a single mom."

Cade echoed Caroline's challenges in paying costs given childcare responsibilities. Cade knew that he wouldn't be discharged from private probation until he paid the full amount of his fine, but he often had to choose between making financial payments and providing for family: "Yeah, he [the judge] was just, 'Why you ain't paid?' 'Man, I got four kids. I'm paying bills and it's hard. It's rough.' He like, 'Well, try to get it something paid. Blah, blah, blah, if you want to get off probation. That the key to getting off is paying your fine.' Life is a struggle."

Even small fees were hard to pay given that participants were often juggling multiple financial responsibilities, common themes that emerge in other studies of individuals under correctional control (Pleggenkuhle 2018; Link 2019; Shannon 2020).

\section{HIDDEN COSTS}

Individuals on supervision and decisionmakers we interviewed argued that because private probation companies were profit focused, conditions of compliance were ordered to help cover the costs of operations or increase profits, or both. The costs for private programming, particularly treatment classes and services, were often not described to participants at the time of sentencing. For example, many courts had a list of go-to programs, which potentially limits competition in this space and may increase the potential for conflicts of interest.

Drug treatment was the most common sentenced sanction associated with private probation. A local attorney in Missouri discussed the frequent use of private probation for "virtually any" municipal drug case, which often involves the possession of a small amount of marijuana. He explained, "if you get locked up on a drug charge, more than likely than not you're going to have at very minimum a requirement that you sign up for the random drug screening program with private correctional services." Indi- 
viduals are randomly screened and can be called six days a week and asked to provide a sample within a three-hour window. If they are not able to provide a sample or the test is positive, the infraction is reported to the judge and a violation hearing is scheduled. Further, in both states, we observed that many participants were ordered to complete regular drug testing, even if the crime was not drug related or the individual did not indicate that substance use motivated the crime.

In both states, the process of determining substance abuse treatment is outsourced to a private treatment provider who has the ultimate authority to mandate the length and nature of the treatment and requisite costs. This assessment process was unclear to litigants, and most agreed to participate without the assistance of legal counsel. A municipal court judge from a midsize community in Missouri described the process he uses to order individuals to treatment: "If they see somebody they think has an issue that needs to be addressed, then we'll send them to get an assessment. There's three or four providers around here close. Get an assessment and sometimes it says come back and just do some extra counseling. Sometimes it says, kind of like, you need to maybe have a weekend intervention or some of that. Occasionally it'll come back that this person's got issues and needs long-term treatment, so they try to find a treatment program that can do that."

This judge perceived it as his duty to address the needs of individuals who came before him, even those apart from the nature of the criminal conviction. In practice, however, regardless of potential benefit from treatment, the programs were quite coercive and come with financial and time costs (Phelps and Ruhland 2021).

The forceful nature of such "care" is even more pronounced when individuals are supervised by private agencies that may be more inclined to enforce compliance for the sake of economic gain. Private probation also creates perverse incentives for increasing total punishment through its payment structures. In Missouri, for example, private probation companies are paid for violation reports, which leads to increased scrutiny of probationers' behavior and a greater likelihood of additional punish- ment via incarceration if violated. A state probation officer in Missouri believed that the private probation companies used this assessment process to add conditions for supervision that came with costs. As noted, private probation companies in Missouri are limited to charging $\$ 50$ per month for supervision fees; they can, however, assess additional costs for drug testing and other supervision elements that increase the cost of supervision to the individual and potential profits for the company. A local state probation officer described the process: "There is a limit, but how they get around it ... let's say for example a guy is on probation for petty larceny. What private probations do, they say okay you're on private probation now, we're administering ... you have to do drug screen, and you have to do drug screen through us. And they add on all these additional services that the client is responsible for. And if the client doesn't partake in that stuff then they're in violation of their probation. And the next thing you know, they're going back to court."

As the participant explained, the costs of private probation are many and involve several requisites for compliance. This theme is echoed by individuals under private control. Charles, a participant from Georgia, expressed cynicism with the process and felt that the sanctions were economically focused: "They try to make you go through a whole bunch of stuff that you don't need to be going through, like anger management, other classes ... All that extra stuff that you don't need to do all that. It was breaking a lamp. Why do I have to do all the extra stuff? They just trying to make money off you. That's all they try to do."

One Missouri defense attorney explained how this works relative to felony probation, which is run entirely by the state:

The private company, because they get paid for every violation report, they are completely out to get my clients. They will violate them for any little slip they find, they'll file a violation report. The felony violation is probation and parole. So, they actually lose their funding if they violate a person, that person goes to the penitentiary. Then, the state funding that was going to probation 
and parole goes to the Department of Corrections. They lose money if they violate someone. It's in their best interest to work with them and not violate them when something small, when there are small transgressions. That's one of the things that was very interesting to me was that felony probation is just a better probation to be on than misdemeanor (probation).

The attorney contended that the private probation company was incentivized to violate clients, different from state probation. Given the potential personal and financial costs of a violation report, individuals being sanctioned for misdemeanors or ordinance violations potentially face an increased likelihood of failure simply because of the nature of the supervision regime. The findings comport with others of this type that warn against the use of private correctional systems that introduce financial incentives that may undermine the primary goals of correctional and increase the potential negative outcomes for individuals under supervision (Harris, Smith, and Obara 2019; Montes and Morgan 2020).

Overall, the costs of private probation are substantial. The complete cost of probation supervision is seldom announced in court, thus the full financial burden for low-level offenses often comes as a surprise to defendants, who are afforded little due process and provided even less clarity in this opaque system of multilayered costs.

\section{RITUALS OF COMPLIANCE}

Participants on private probation also found it difficult to comply with sanctions that were often multilayered, time-delimited, and required frequent trips to court. A clerk in a rural Missouri municipal court described the procedural hassles that come with private probation: "They can put you on supervised private probation. They can make you take drug tests every week, they can make you do 250 hours of community service, they can make you wear, maybe, electronic equipment. In other words, probation can make you do things and restrict movement and activity."

A private probation officer in Georgia described how much of this performance (compli- ance with reporting) relates to ensuring monetary sanctions are paid: “I don't think it's that their behavior needs to be monitored. It's just so that they're keeping in touch and they're letting us know what's going on with getting the fines paid. ... Usually it's gonna be, 'All right, have you sent your payment? When are you gonna do that? What amount can you send? Are you having trouble with this, what do we need to do?' Just to make sure that the case gets taken care of and closed out."

However, judges often set so many parameters of the probation sentence, which can potentially increase the challenges for the defendant. Evidence from court observations in Georgia highlighted this theme.

All of the defendants were sentenced to complete module 2 (the teen driving course), "a driving improvement program." The judge noted that the program should only take three weekends, though he gave all defendants four months to complete the program. He then gave possible excuses for not completing the program ("my dog died," "I had a demanding professor," "I had fall training," "I had spring rehearsals"). He went on to say that none of those excuses are valid given the amount of time he is allowing to complete the program.

The judge in this case minimized the time it would take to complete the course, which was the equivalent of six working days, for a municipal traffic infraction. In another observed court interaction in Missouri, the judge required thirty hours of community service within sixty days, as a condition of private probation, for a probation violation. The individual had yet to meet those requirements and the judge repeated the requirement and threatened jail time for noncompliance. In Georgia, we observed two judges in different jurisdictions who indicated that the defendant should buy a toothbrush to use in jail if they did not comply.

The judge addressed one defendant, a young Black woman, saying that he had the ability to fine her up to $\$ 1,000$ and twelve months in jail. He then said, "if you come back having not completed the program, you don't have to worry about the fine, but you do need to bring a toothbrush."

Dale described a similar experience that he characterized as "harassment" as part of his 
regular check-in with the judge: "If you ain't complying with everything they say you had to do for the paying a lot of money or doing all your community service hours, by they standards, like in a certain time, they make it, like, they be harassing you. Threatening you going to jail and doing, they taking you to court. That's fine. Take me to court. Ain't nothing going to change. You take me to court today, I'm still in the same situation. So you feel?"

Dale was mandated to attend multiple court dates, which he found extremely stressful because he was having trouble paying the requisite supervision fees and completing the community service hours. He felt that he could not possibly comply with community service and keep his job, and the time costs of attending court further diminished his available time. As his observations suggest, the numerous, sometimes competing conditions of supervision create a "piling on" effect by which probation and LFO sentences become onerous (Bing, Pettit, and Slavinski 2022, this volume; Uggen and Stewart 2015). Although he felt that the judge was trying to use jail time to encourage payment, he felt that without a fundamental change to his current life situation that he could not meet the time-delimited request (Martin, Spencer-Suarez, and Kirk 2022, this issue).

This participant expressed a willingness to accept some punishment for their wrongdoing but felt that being under subsequent supervision and paying LFOs was "ridiculous." We have many such examples from participants who said that one form of punishment is fair (such as fines only), but once they receive more than one punishment, such as a fine plus community service or jail, their punishment is out of proportion to what they had done. Many, like a participant from Georgia, felt that it should be "one or the other." "I don't like the fact that it's community service and the fine. I think they should make it one or the other."

This "piling on" effect can become even more cumbersome when an individual is under supervision by more than one probation agency. In Georgia, this is possible because felony probation supervision is state run but misdemeanor probation is locally administered, often by private probation companies. If an individual is sentenced to both felony and mis- demeanor offenses in the same jurisdiction, they are frequently supervised by the state. But if convictions occur in different jurisdictions, such coordination is less likely. Chris described how having to report to multiple supervising agencies, both public and private, creates an untenable situation:

At one time I had state probation, misdemeanor probation running at the same time. They wanted me to make payments here and they wanted me to make payments there, and I explained it to them, "I barely have enough money to pay you but they want me to pay them too. They want me to report here and they also want me to report over there. Both of y'all want me to be working." It's impossible to actually please everybody. Even if I was just reporting to one, again it's impossible to please your employer and the probation office at the same time. It's a big strain.

They point out that some people who have an understanding employer can find ways to manage the difficult balancing act. Chris captured the feeling of being torn between myriad competing expectations not only from multiple supervising agencies but also from employers as "like a constant burning torturous feeling." Maintaining employment is often a condition of probation and necessary for having the ability to pay off LFO debt. Yet, as participants explain, these conflicting pressures create a situation in which fulfilling these sentences is out of reach because "it is impossible to actually please everybody."

The process of compliance includes performative requirements which can also be taxing to defendants (Kohler-Hausmann 2013). Judges weighed heavily compliance with LFOs as a key consideration in deciding outcomes on probation. Paying LFOs is a significant indicator of overall compliance with probation, but "just paying something" can be sufficient (see also Pattillo and Kirk 2021). An individual on probation in Georgia described their experience. "They want you to pay something no matter what. They don't care if it's $\$ 10$ to $\$ 100$ but as long as you put something toward your fine or restitution it shows that you're trying." A similar event was observed in court in Missouri, 
where attorneys frequently use adherence to probation guidelines as a signal for compliance. In court observations, a defense attorney asked that their client be released from private probation given his compliance with electronic monitoring: "[My client] says from May to July 2009 is when all of these priors took place. He cannot explain why the defendant did these during this time, must have 'gone crazy, but he pled guilty and went to prison for those. $\mathrm{He}$ has been on (electronic) monitoring for two months now with no violations and has a job working 8 hours a day. He has shown the Court he should be dismissed from probation as he "can follow rules and be a productive member of society."

Adherence to other conditions that also incur financial costs, such as electronic monitoring, is even more important for demonstrating. compliance. At the same time, noncompliance with the same conditions due to high costs or other factors was rarely considered. Thus, although the official reason for noncompliance is that they did not successfully complete their class or treatment, the real reason is that they could not afford to pay the fees. An attorney in Georgia highlighted this phenomenon: "Yeah, because they were ordered to complete that, and if it comes in that those classes come with fees and charges and they can't pay that and they get kicked out of class, well they're violating probation at that point."

Overall, we observed a bifurcated system. Defendants without means are expected to display contrition and accountability for their crimes through regular court appearances (Martin, Spencer-Suarez, and Kirk 2022, this volume); we consistently observed that these procedural performances of compliance were in fact routinely waived or avoided by people with economic means or legal representation. In fact, we observed people who were willing to pay more money for fines if it meant they could avoid the procedural hassle of coming to court again. Such interactions were not universal, however. Practices vary, but we did observe judges reducing economic sanctions in response to defendants' compliance with other terms of private probation. In neither state, was it clear when and how judges make the decision to reduce final obligations.
DISPROPORTIONALITY OF

\section{PRIVATE PROBATION}

Our data reveal that the principle of proportionality in punishment is compromised by the combination of probation and LFO sentences along three dimensions, especially when private probation supervision is involved: increased sentence length for nonpayment, collateral consequences, and exploitation. In misdemeanor courts, the intersection of private probation and LFO sentences compromises proportionality when it leads to longer sentences overall, particularly for petty offenses such as traffic violations or possession of a small amount of marijuana, for example. In both states, individuals who have money and can readily pay LFOs spend less time on supervision (if any) than those who cannot pay immediately. As a result, several mechanisms enable sentence length to be extended in order to ensure payment of LFOs.

In Missouri, judges can use the length of probation to encourage full payment of monetary sanctions. As one probation officer put it, "There are some judges who are very conscious of those costs. I've even had a judge tell me before that they're not going to let anybody off probation with owed fees, and that includes intervention fees or court costs." Cassie, a participant from Missouri, describes how the threat of extended probation led to borrowing money from her mother to pay off her LFOs: "The \$2,000 I had to borrow money from my mom because it was pressing for me to be able to get released early and not extend my probation. I borrowed the money from her and then whenever I got my taxes this year I paid it back."

Georgia statute prohibits "tolling" or extending probation sentences for nonpayment of fines and fees. Nonetheless, we routinely observed judges sentencing people with multiple misdemeanor charges to consecutive rather than concurrent terms of probation in order to give them more time to pay. This workaround was often posed by court decision-makers as a form of mercy, as one Georgia judge explained: "The judge indicates that she wants to make all three probation sentences consecutive rather than concurrent (for a total of thirty-six months) in order to 'spread this money out' because of the defendant's pregnancy." 
In both states, people convicted of misdemeanors can be placed on pay-only probation. This type of sentence is a way of de facto extending time on probation supervision because such individuals would otherwise not be placed on probation at all if they had the means to pay. In Georgia, individuals can be sentenced to up to twelve months on pay-only probation for each offense and stay on until they pay their LFOs in full or until twelve months expire. Being placed on pay-only probation was often framed by court actors, especially judges, as setting people up to succeed by giving them more time to pay. One judge in a high-volume municipal court we observed in Georgia said he was "glad to do it" after a defendant accepted his offer to be placed on private probation supervision for twenty-four months because she could not pay her traffic fines that day. However, for many, this system only served to entangle people in the system for longer periods and often bound people to greater surveillance and legal precarity (Pattillo and Kirk 2021). Our field notes in one Georgia jurisdiction provide an example: "Defendant pleads guilty to both counts. He is charged with \$256 for the speeding charge and $\$ 1,506$ for the drug charge. The case was processed quickly. 'Is twelve months enough time to get that paid off?' the judge asks. 'No, because I can't work,' the defendant responds. Judge says that he does not want to set anyone up for failure and attorney and agrees to twenty-four months on probation to get the fine paid off."

In Georgia, probation agencies can charge supervision fees only for the first three months. But, if fines are converted to community service then the supervision fee is reinstated, which in practice contradicts the provision of community service for those who are indigent.

The payment process can continue indefinitely in Missouri. Individuals in some of the municipal courts we observed were regularly placed on pay-only dockets. As long as the individual appeared in court, no formal sanctioning was applied beyond the continued "process as the punishment," whereby the individual is indefinitely tied to the courthouse. Pay-only probation was not a universal feature in Missouri. Some municipal courts actors elected to monitor payment in-house. Although individu- als in these courts did face the procedural hassle of regularly returning to court, the additional third-party costs associated with private probation were not assessed.

Probation sentences can also increase an individual's total punishment exposure by exacerbating collateral consequences, including difficulty securing employment or housing. Credit problems are another byproduct of the pressure to pay off LFOs to fulfill the conditions of probation. Caroline from Georgia explained:

I went ahead and put in for a credit card and I don't want to do that. I don't. But I feel like that's my only option to kind of walk away from it. It's not fair. And now I have to go through this whole situation where in two weeks I gotta come back to her and see if I do qualify for community service and if I don't qualify for the community service, yeah I'm probably just going to have to put it all on the credit card and just let them. I'll just pay it off on the credit card that way. And I don't want to do that cause I'm like, I'm trying my best to keep it clean and keep rising the score cause I want to get a home.

In this instance, and many others, both credit and securing housing are compromised as a result of having few options to pay LFOs in order to minimize time spent on probation (Pattillo et al. 2022, this volume). Lack of transportation due to license revocation as a condition of probation is another collateral consequence that limits defendants' ability to secure and maintain employment. One judge in a Georgia court explained: "If you don't finish your probation terms, it's going to be harder to get your license back. It may be because there's something substantive you haven't done, like you haven't taken your risk reduction class. But if you don't show up for probation, and you don't pay your probation fines and fees, and you don't do what you're ordered to do, it's going to be harder to get your license back, one way or the other."

In both states, private probation is frequently viewed as a form of exploitation by participants and even by some court actors. This aspect of private probation supervision undermines proportionality because the fees they 
charge are perceived as out of proportion severity of the criminal offense. Moreover, individuals on private probation are not offered the case management and services that are part of traditional felony probation, and many questioned what the fees were used for. As one judge in Missouri put it, "I'm not crazy about some of the private probation companies just because they're making money, that's what their job is to make money. Somebody owns that company and they want to do it for profit." On a similar note, a state probation officer called private probation a "scam" and part of the "good ole boy system" because "their fees are exorbitant to what their costs are." Joe in Georgia described this critique from the perspective of someone on private probation supervision, "I mean it ain't, it didn't cost them nothing to ... for me to make a payment, you know. Plus they get paid when you go to jail, so ... you know, like seventy-five dollars a day, so I don't see where it costs 'em."

Overall, we find a striking contrast between the power of judges and other court actors to impose arduous sentences for low-level offenses and the lack of recourse available to defendants who were unable to comply because of the financial strain. Individuals who didn't have the means to comply were returned to court frequently, subjected to more intense scrutiny by private probation companies that have a profit incentive to increase costs, and often had the span of punishment extended, sometimes indefinitely (Pattillo and Kirk 2021). As Caroline, a participant from Georgia, put it, "I don't want to have to keep paying more money for more time. That's not fair."

\section{DISCUSSION AND CONCLUSION}

Probation is commonplace and the costs associated with this sanction have increased in recent years (Ruhland 2019; Link, Hyatt, and Ruhland 2020), but much less is known about the processes and costs of private probation. This article provides insight into private probation in Georgia and Missouri where private probation is widely used in lower courts and most often imposed for misdemeanor, traffic, and municipal ordinance offenses. Given the growth in misdemeanor violations (Mayson and Stevenson 2020), this work highlights a unique element of correctional control that has largely been hidden.

Overall, we found many similarities between the two states in policy and practice of private probation. In both states, private probation costs are routinely imposed, sometimes hidden, and vary substantially at the local level. One key difference in costs is that Missouri law limits probation fees charged by private entities to $\$ 50$ per month, but Georgia does not have any statutorily imposed limits on supervision fees for misdemeanor probation. By and large, rituals of compliance across the two states are similarly burdensome and expansive. We also found several important differences in terms of proportionality, at least in state policy. Whereas the Missouri statute allows for misdemeanor probation terms to be extended if fines and fees go unpaid, Georgia law prohibits the tolling of probation sentences for unpaid monetary sanctions. Purportedly, this limits the ability of decision-makers to add time to probation sentences. Yet we also observed judges imposing consecutive sentences for multiple charges in order to circumvent this limitation. In addition, recent reforms limit the number of months that individuals sentenced to payonly probation in Georgia can be charged probation fees, whereas Missouri has no such statutory limit. Georgia has also recently formed an oversight board for misdemeanor probation within the state Department of Community Supervision, but Missouri lacks any statewide oversight of private probation companies.

In many ways, the results from the analyses mimic that found in studies of traditional felony or state-run probation systems (Ruhland, Holmes, and Petkus 2020). Supervision fees and compliance costs are regularly assessed and many individuals face challenges paying even the smallest of sanctions (Link 2019; Pleggenkuhle 2018). Individuals supervised on private probation are routinely assessed legal and financial obligations that can include court costs, supervision fees, and treatment costs, among others. Conditions of probation are also cumbersome and for many can be coercive, making compliance difficult (Brett, Khoshkhoo, and Nagrecha 2020).

However, private probation departs from traditional probation in several ways. First, the 
costs and procedural requirements for private probation are often disproportionate to the nature of the criminal behavior being sanctioned. Individuals enter the municipal court system for minor offenses, including traffic and ordinance violations. Yet the totality of costs that can be assessed is quite large and in some cases surpasses financial assessments for felony probation. As Alexes Harris and her colleagues (2019) contend, the private probation process includes several "cost points" and the layered nature of sanctioning makes compliance difficult for those without economic means. For example, participants routinely noted that they were mandated to programming, such as safe driving classes or drug treatment, as part of the criminal sanction as well as to the costs of supervision. These programming costs were often not described at the time of sentencing and could be extended for long periods, further tethering the individual to the justice system (Pattillo and Kirk 2021). It is this shadow carceral state (Beckett and Murakawa 2012) that participants found most distressing. In fact, the private probation system is legislatively designed to be predatory: in many states, such as Missouri, it is mandated to be client funded, which shifts the responsibility for punishment from the state to the individual client, a theme that emerges in studies of other municipal court functions (Huebner and Giuffre 2022, this issue). The use of private systems also incentivizes extended control.

Second, little if any assessment of the ability to pay is undertaken in lower courts, which offered participants scant reprieve from payment. In our court observations, we rarely saw judges explain the costs of private probation or inquire about the defendant's financial situation. Costs for court-mandated programming were rarely described to litigants, and the financial situation was not considered by private companies, which furthered the economic indebtedness of participants. Noncompliance leads to compounded fiscal and procedural costs as well as sentence length, all of which lead to disproportionate sentences for minor offenses.

Finally, individuals on private probation have few procedural rights, even fewer than those afforded in state supervision systems. In- dividuals do not have the same legal rights and access to counsel they would have in a felony court (Williams, Schiraldi, and Bradner 2019). Instead, the procedural costs for some on private probation can be higher (Latessa and Lovins 2019). One example is pay-only probation that affords additional punishment to only those who cannot pay. These sentences can undermine the principle of proportionality by elongating the period of supervision simply for the inability to pay (see also Pattillo and Kirk 2021). In other cases, individuals on private probation are required to attend court on a regular basis, which often includes substantial procedural hassles, and time was often seen as a resource that could be controlled by the court but was often in short supply given the multilayered nature of the sanctions and the limited means of participants (Martin, Spencer-Suarez, and Kirk 2022, this issue). Taken together, these factors reveal several dimensions along which the costs-financial, temporal, and procedural-add up to sentences that far outpace the seriousness of the minor offenses that land individuals on private probation.

Several policy implications follow from this research, including the elimination of the use of private agencies for surveillance altogether. As stated, the current funding models provide incentives to extend probation and increase costs to the detriment of the individual (Harris, Smith, and Obara 2019). In the case of private probation, the costs are often disproportionate to the nature of the offense and exploitative. As Brittany Friedman and her colleagues argue (2022, this volume), eliminating monetary sanctions whenever possible includes decriminalizing traffic offenses that ensnare people in some states, including Georgia and Missouri, in extended periods of onerous supervision and additional costs that generate profits for private companies.

In terms of procedural protections, public defenders, for the most part, are not used in municipal courts. In court observations, it is clear that many citizens entering the courts, often for the first time, do not full understand their legal rights. We observed clients arriving at the wrong location, many did not have the required materials for their case (proof of insurance, financial documentation), and the re- 
search team was often approached for assistance (Spencer-Suarez and Martin 2021). Individuals on private probation can be punished harshly for minor crimes yet not afforded due process protections. Moreover, private probation does not offer the same types of programming offered to individuals on state probation. The inequalities in the systems and lack of data on the potential efficacy of these models call into question the need for private probation in the first place.

If states are going to maintain probation systems for individuals in lower courts, then the oversight of private probation should be the same as that afforded to individuals; comparable procedural elements should be used with both groups, a theme echoed by others doing work in this space (Latessa and Lovins 2019). In terms of oversight, the Georgia General Assembly has recently implemented reforms that empower the state Department of Community Supervision to ensure that private and governmental misdemeanor probation agencies comply with state law, ${ }^{13}$ including creating a Misdemeanor Probation Oversight Unit, reviewing the uniform professional standards and uniform contract standards, approving orientation training and continuing education for misdemeanor probation officers, and collecting quarterly data from misdemeanor (private and public) agencies. Despite reforms, the narratives documented by participants in Georgia and Missouri, a state with little oversight, were similar, which raises concerns over the efficacy of existing regulatory models.

This study provides a unique perspective on private probation services, but it is not without limitations. It centers on decision-makers in the court and corrections systems, and we were not able to collect information on individuals and companies who provide services and treatment to those involved in the criminal legal system. Despite many attempts in both states, we were not able to speak directly to many employees who provide private services. It is important to broaden the work of this type to capture the unique voices of service providers, first, to better understand the nuances of this work and, second, to document potential best practices in both public and private systems by comparing outcomes in this sphere of institutional corrections (Duwe and Clark 2013; Wooldredge and Cochran 2019).

The results from this research suggest that private probation is a regular part of the punishment regime for misdemeanors and ordinance violations in Georgia and Missouri and has a disparate impact on people with fewer economic means. Much remains to be learned about this element of control, but the results presented here suggest that the conditions of supervision are arduous and often include layered punishments that are hidden from regulation and disproportionate to the severity of the offense. Moreover, individuals with fewer economic means are tied to the system for a longer period, which reflects larger inequalities of the carceral system. Learning more about the system of private probation would shed light on the broader system of punishment as a whole (Montes and Mears 2019).

\section{REFERENCES}

Alarid, Leanne Fiftal, and Christine S. Schloss. 2009. "Attorney Views on the Use of Private Agencies for Probation Supervision and Treatment." International Journal of Offender Therapy and Comparative Criminology 53(3): 278-91.

Albin-Lackey, Chris. 2014. Profiting from Probation America's "Offender-Funded" Probation Industry. New York: New York Human Rights Watch.

Appleman, Laura I. 2016. "Nickel and Dimed into Incarceration: Cash Register Justice in the Criminal Justice System." Boston College Law Review 57(5): 1483-541.

Bannon, Alicia, Mitali Nagrecha, and Rebekah Diller. 2010. Criminal Justice Debt: A Barrier to Re-entry. New York: Brennan Center for Justice.

Beckett, Katherine, and Alexes Harris. 2011. “On Cash and Conviction" Criminology \& Public Policy 10(3): 509-37. DOI: https://doi.org/10.1111/j.1745 -9133.2011.00726.x.

Beckett, Katherine, and Naomi Murakawa. 2012. “Mapping the Shadow Carceral State: Toward an Institutionally Capacious Approach to Punishment." Theoretical Criminology 16(2): 221-44.

Bellacicco, Sarah Dolisca. 2013. "Safe Haven No Longer: The Role of Georgia Courts and Private 
Probation Companies in Sustaining a De Facto Debtors' Prison System." Georgia Law Review 48(3): 229-66.

Biernacki, Patrick, and Dan Waldorf. 1981. “Snowball Sampling: Problems and Techniques of Chain Referral Sampling." Sociological Methods \& Research 10(2): 141-63.

Bing, Lindsay, Becky Pettit, and Ilya Slavinski. 2022. “Incomparable Punishments: How Economic Inequality Contributes to the Disparate Impact of Legal Fines and Fees." RSF: The Russell Sage Foundation Journal of the Social Sciences 8(2): 118-36. DOI: https://doi.org/10.7758/RSF.2022 8.2.06.

Brett, Sharon, Neda Khoshkhoo, and Mitali Nagrecha. 2020. Paying on Probation: How Financial Sanctions Intersect with Probation to Target, Trap, and Punish People Who Cannot Pay. Boston, Mass.: Harvard Law School.

Cadigan, Michele, and Gabriela Kirk. 2020. “On Thin Ice: Bureaucratic Processes of Monetary Sanctions and Job Insecurity." RSF: The Russell Sage Foundation Journal of the Social Sciences 6(1): 113-31. DOI: https://doi.org/10.7758/RSF.2020 .6.1.05.

Cadigan, Michele, and Tyler Smith. 2021. "'Are You Able-Bodied?' Embodying Accountability in the Modern Criminal Justice System." Journal of Contemporary Criminal Justice 37(1): 25-44.

Charmaz, Kathy. 2006. Constructing Grounded Theory: A Practical Guide Through Qualitative Research. London: Sage Publications.

Colgan, Beth. 2014. “Reviving the Excessive Fines Clause." California Law Review 277(2): 284-95.

Corbett, Ronald P. 2015. "The Burdens of Leniency: The Changing Face of Probation." Minnesota Law Review 99: 1697-732.

Council of State Government Justice Center. 2016. Justice Reinvestment in Georgia. Accessed November 16, 2021. https://csgjusticecenter.org /projects/justice-reinvestment/past-states /georgia/ Washington, DC: Council of State Governments.

Diller, Rebekah, Judith Greene, and Michelle Jacobs. 2009. Maryland's Parole Supervision Fee: A Barrier to Reentry. New York: Brennan Center for Justice.

Doherty, Fiona. 2016. "Obey All Laws and Be Good: Probation and the Meaning of Recidivism." Georgetown Law Journal 104(2): 291-354.

Duwe, Grant, and Valerie Clark. 2013. “The Effects of Private Prison Confinement on Offender Recidivism: Evidence from Minnesota." Criminal Justice Review 38(3): 375-94.

Evans, Douglas. 2014. The Debt Penalty-Exposing the Financial Barriers to Offender Reintegration. New York: John Jay College of Criminal Justice.

Fernandes, April D., Michele Cadigan, Frank Edwards, and Alexes Harris. 2019. "Monetary Sanctions: A Review of Revenue Generation, Legal Challenges, and Reform." Annual Review of Law and Social Science 15(1): 397-413.

Friedman, Brittany, Alexes Harris, Beth M. Huebner, Karin D. Martin, Becky Pettit, Sarah K.S. Shannon, and Bryan L. Sykes. 2022. "What Is Wrong with Monetary Sanctions? Directions for Policy, Practice, and Research." RSF: The Russell Sage Foundation Journal of the Social Sciences 8(1): 221-43. DOI: https://doi.org/10.7758/RSF.2022 .8.1.10.

Harris, Alexes, Beth M. Huebner, Karin D. Martin, Mary Pattillo, Becky Pettit, Bryan L. Sykes, Christopher Uggen, and April D. Fernandes. 2017. Monetary Sanctions in the Criminal Justice System. New York: Arnold Foundation.

Harris, Alexes, Mary Pattillo, and Bryan L. Sykes. 2022. "Studying the System of Monetary Sanctions." RSF: The Russell Sage Foundation Journal of the Social Sciences 8(1): 1-33. DOI: https://doi. org/10.7758/RSF.2022.8.1.01.

Harris, Alexes, Tyler Smith, and Emmi Obara. 2019. "Justice 'Cost Points.'" Criminology and Public Policy 18(2): 343-59.

Heaton, Paul, Sandra Mayson, and Megan Stevenson. 2017. "The Downstream Consequences of Misdemeanor Pretrial Detention." Stanford Law Review 69(3): 711-94.

Huebner, Beth M., and Andrea Giuffre. 2022. “Reinforcing the Web of Municipal Courts: Evidence and Implications Post-Ferguson." RSF: The Russell Sage Foundation Journal of the Social Sciences 8(1): 108-27. DOI: https://doi.org/10.7758 /RSF.2022.8.1.05.

Kaeble, Danielle, and Mariel Alper. 2020. Probation and Parole in the United States, 2017-2018. Washington, DC: Bureau of Justice Statistics.

Klingele, Cecelia. 2013. "Rethinking the Use of Community Supervision." Journal of Criminal Law and Criminology 103(4): 1015-70.

Kohler-Hausmann, Issa. 2013. “Misdemeanor Justice: Control Without Conviction." American Journal of Sociology 119(2): 351-93. 
- 2018. Misdemeanorland: Criminal Courts and Social Control in an Age of Broken Windows Policing. Princeton, N.J.: Princeton University Press.

Latessa, Edward J., and Lori Brusman Lovins. 2019. "Privatization of Community Corrections." Criminology \& Public Policy 18(2): 323-41.

Link, Nathan W. 2019. “Criminal Justice Debt During the Prisoner Reintegration Process: Who Has It and How Much?" Criminal Justice and Behavior 46(1): 154-72.

Link, Nathan W., Jordan Hyatt, and Ebony Ruhland. 2020. “Monetary Sanctions, Legal and Collateral Consequences, and Probation and Parole: Where Do We Go From Here?" UCLA Criminal Justice Law Review 4(1): 200-211.

Lofland, J., David A. Snow, Leon A. Anderson, and Lyn H. Lofland. 2005. Analyzing Social Settings: A Guide to Qualitative Observation and Analysis. New York: Wadsworth.

Martin, Karin D., Kimberly Spencer-Suarez, and Gabriela Kirk. 2022. “Pay or Display: Monetary Sanctions and the Performance of Accountability and Procedural Integrity in New York and Illinois Courts." RSF: The Russell Sage Foundation Journal of the Social Sciences 8(1): 128-47. DOI: https://doi.org/10.7758/RSF.2022.8.1.06.

Martin, Karin D., Bryan L. Sykes, Sarah K.S. Shannon, Frank Edwards, and Alexes Harris. 2018. "Monetary Sanctions: Legal Financial Obligations in US Systems of Justice." Annual Review of Criminology 1(1): 471-95.

Maruschak, Laura, and Todd D. Minton. 2020. Correctional Populations in the United States, 20172018. Washington, DC: US Department of Justice.

Mayson, Sandra, and Megan Stevenson. 2020. "Misdemeanors by the Numbers." Boston College Law Review 61(3).

Miles, Matthew B., and A. Michael Huberman. 1993. Qualitative Data Analysis: An Expanded Sourcebook. Thousand Oaks, Calif: Sage Publications. Montes, Andrea N., and Daniel P. Mears. 2019. "Privatized Corrections in the 21st Century." Criminology \& Public Policy 18(2): 217-39.

Montes, Andrea N., and Skyler J. Morgan. 2020. "Helpful or Harmful? Theorizing Privatized Corrections: Findings from a Qualitative Study." Journal of Crime and Justice. Published online November 20. Accessed August 10, 2021. https:// doi.org/10.1080/0735648X.2020.1820368.

Morris, Norval, and Michael Tonry. 1990. Between
Prison and Probation: Intermediate Punishments in a Rational Sentencing System. New York: Oxford University Press.

Natapoff, Alexandra. 2018. Punishment Without Crime: How Our Massive Misdemeanor System Traps the Innocent and Makes America More Unequal. New York: Basic Books.

O'Malley, Pat. 1998. "Imagining Insurance Risk, Thrift and Industrial Life Insurance in Britain." Connecticut Insurance Law Journal 5(2): 676703.

Pattillo, Mary, Erica Banks, Brian Sargent, and Daniel J. Boches. 2022. “Monetary Sanctions and Housing Instability." RSF: The Russell Sage Foundation Journal of Social Sciences 8(2): 57-75. DOI: https://doi.org/10.7758/RSF.2022.8.2.03.

Pattillo, Mary, and Gabriela Kirk. 2021. “Layaway Freedom: Coercive Financialization in the Criminal Legal System." American Journal of Sociology 126(4): 1-41.

Petersilia, Joan. 2003. When Prisoners Come Home: Parole and Prisoner Reentry. New York: Oxford University Press.

Phelps, Michelle S. 2020. “Mass Probation from Micro to Macro: Tracing the Expansion and Consequences of Community Supervision." Annual Review of Criminology 3(1): 261-79.

Phelps, Michelle S., and Ebony L Ruhland. 2021. "Governing Marginality: Coercion and Care in Probation." Social Problems. Published online January 6. Accessed August 10, 2021. https://doi .org/10.1093/socpro/spaa060.

Pleggenkuhle, Breanne. 2018. “The Financial Cost of a Criminal Conviction: Context and Consequences." Criminal Justice and Behavior 45(1): 121-45.

Ramachandra, Komala. 2018. "Set Up to Fail" The Impact of Offender-Funded Private Probation on the Poor. New York: New York Human Rights Watch.

Rappleye, Hannah, and Lisa Riodian-Seville. 2012. “'Cash Register Justice: Private Probation Services Face Legal Counterattack." NBC News, October 24. Accessed August 10, 2021. https:// www.nbcnews.com/news/investigations/cash -register-justice-private-probation-services-face -legal-counterattack-flna1c6646131.

Rosenthal, Alan, and Marsha Weissman. 2007. Sentencing for Dollars: The Financial Consequences of a Criminal Conviction. Syracuse, N.Y.: Center for Community Alternatives Justice Strategies. 
Ruhland, Ebony. 2019. "It's All About the Money: An Exploration of Probation Fees." Corrections 6(1): 65-84. https://doi.org/10.1080/23774657.2018 1564635.

Ruhland, Ebony, Bryan Holmes, and Amber Petkus. 2020. "The Role of Fines and Fees on Probation Outcomes." Criminal Justice and Behavior 47(10): 1244-63.

Schloss, Christine S., and Leanne F. Alarid. 2007. "Standards in the Privatization of Probation Services: A Statutory Analysis." Criminal Justice Review 32(3): 233-45.

Shannon, Sarah. 2020. “Probation and Monetary Sanctions in Georgia: Evidence from a MultiMethod Study." Georgia Law Review 54(4): 121334.

Spencer-Suarez, Kimberly, and Karin D. Martin. 2021. “Navigating the Monetary Sanctions Maze: Understanding and Confusion Among Criminal Legal Debtors." Journal of Contemporary Criminal Justice 37(1): 4-24.
Stevenson, Megan, and Sandra Mayson. 2018. "The Scale of Misdemeanor Justice." Boston University Law Review 98(3): 731-78.

Teague, Michael. 2011. “Probation in America: Armed, Private and Unaffordable?" Probation Journal 58(4): 317-32.

Uggen, Christopher, and Robert Stewart. 2015. “Piling On: Collateral Consequences and Community Supervision." Minnesota Law Review 99(5): 1871-910.

Williams, Jarred, Vincent Schiraldi, and Kendra Bradner. 2019. The Wisconsin Community Corrections Story. New York: Columbia University Justice Lab.

Wilson, Justin P. 2018. Private Probation Services Council: Performance Audit Report. Nashville: Tennessee Department of the Auditor.

Wooldredge, John, and Joshua C. Cochran. 2019. “Equal or Not? Private Versus Public Corrections Services, Programming, and Climate." Criminology \& Public Policy 18(2): 295-321. 